\title{
Actuar per parlar. La dramatització com a instrument didàctic per a l’adquisició lingüística i la formació literària
}

\section{Antonio Luengo Bravo \\ Universitat Autònoma de Barcelona}

Un dels principals reptes que els centres educatius del nostre país han hagut d'assumir en els últims anys ha estat l'educació i la integració personal i cultural d'alumnat provinent de diferents indrets en un món canviant i cada cop més globalitzat. Les aules han hagut de respondre a aquesta complexitat lingüística i cultural a través de pràctiques diverses que, en l'acollida inicial, han tingut l'objectiu d'integrar lingüísticament i cultural les persones nouvingudes i propiciar les condicions per a la incorporació de l'alumnat a les aules ordinàries.

En una societat en què la paraula i, sobretot, els textos escrits són primordials per a qualsevol tasca quotidiana, laboral i educativa, l'aprenentatge de la llengua del país ha estat un dels focus principals a les aules d'acollida. Les aules d'acollida han estat adoptades per alguns centres educatius com a espais de treball intensiu amb alumnat nouvingut, que surt de l'aula ordinària en determinades hores lectives per reforçar aspectes com la llengua. ${ }^{1}$

Les aules d'acollida, tot i la gran complexitat que aborden, són instruments privilegiats, tant pel nombre d'alumnes, com per la possibilitat de treballar amb metodologies diverses i innovadores. Els i les educadores dels nostres centres han dut a terme pràctiques diverses i s'han servit de múltiples recursos per iniciar l'alumnat nouvingut com a usuari de la llengua catalana, vehicular en l'educació a Catalunya i instrument primordial per a l'ensenyament $\mathrm{i}$ aprenentatge de les diferents àrees del currículum.

La literatura, en aquests contextos, ha de tenir i pot tenir un paper destacat, tant com a portadora de la cultura del país, com en tant que model lingüístic i exponent de la llengua. En aquest sentit $\mathrm{i}$ des de fa cert temps, el grup de recerca GRETEL $^{2}$ ha començat a explorar el paper que juga la literatura en contextos plurilingües i pluriculturals. De l'ampli ventall d'interrogants que sorgeixen al voltant d'aquesta 
qüestió, mostrar de quina manera la literatura pot contribuir a l'aprenentatge lingüístic de l'alumnat nouvingut ens resulta del tot fonamental.

Des del camp de l'ensenyament, s'han desenvolupat diferents estudis que se situen en la línia, assenyalada pel Consell Assessor de la Llengua a 1'Escola (Murgades 2006), d'explorar els avantatges d'integrar l'alumnat nouvingut a través de la literatura:

- La literatura resulta un instrument fonamental per al model d'integració de cultures que es vulgui adoptar, ja que ofereix les formes de ficció i dels referents culturals que cohesionen una comunitat, tot nodrint-ne les imatges de representació social en els diversos nivells de pertinença de cada individu.

- La relació que s'estableix entre l'adolescent i els textos literaris dóna cabuda a les dimensions afectives i col-labora en la construcció de la pròpia identitat.

- La literatura aporta una situació comunicativa concreta que pot englobar diversos tipus de discurs.

Així doncs, el treball amb textos literaris a les aules d'acollida, a més d'afavorir l'aprenentatge de la llengua del país d'acollida, que és un dels objectius primordials de la integració a l'escola de l'alumnat nouvingut, compleix un paper integrador i permet establir un recorregut lector que millori la comprensió i interpretació dels textos literaris.

Nombrosos textos assenyalen que les variables afectives són un factor poderós que influeix en les adquisicions lingüístiques. En aquest sentit, es pot fer referència al treball de Guasch (1999):

Cal atendre, des d'una perspectiva transcurricular, no només els factors cognitius, sinó també els afectius (actitudinals i motivacionals), en tant que tenen un paper fonamental en els processos d'adquisició de llengües. (p. 15)

Les possibilitats que ofereixen els textos literaris per ser treballats a l'aula són il-limitades i inclouen el treball d'aspectes lingüístics i el treball de l'expressió oral i escrita, com, per exemple, l'ús de la llengua oral en les discussions literàries. Es pot fer esment en aquest punt al corpus de textos literaris que ha realitzat Margallo (2008) per al treball de diferents aspects lingüístics i literaris a les aules d'acollida. 
Sense dubte, l'ús oral de la llengua és un dels aspectes en què l'acollida d'alumnat nouvingut ha incidit i ha de seguir incidint, ja que l'expressió oral és un dels trets fonamentals en l'aprenentatge de segones llengües. En aquest sentit les tècniques de dramatització suposen un banc de proves per a l'ús oral del català.

\section{Dramatitzar per aprendre llengua i literatutra}

L'alumnat nouvingut necessita contextos comunicatius per construir el seu aprenentatge, ja que, segons el seu context, pot no haver tingut cap contacte amb les situacions socials d'ús real de la llengua d'acollida, més enllà de l'ús escolar. Això pot provocar reticències a l'hora de parlar català.

En aquest sentit, Casado (2003:29) afirma que el joc dramàtic i el teatre es conceben com un veritable recurs pedagògic que permet desenvolupar les capacitats expressives i, en concret, l'expressió oral. Ofereix la possibilitat de llançar-se a parlar en català, descobrir les pròpies potencialitats i portar-les a la pràctica en la vida escolar i quotidiana.

Tejerina (1994) constata, a més, els beneficis del desenvolupament de l'expressió lingüística amb la cultural. Cada cultura, diu, té les seves particulars expressions facials i posicions corporals i aquestes es veuen reflectides en el sistema comunicatiu de cada llengua.

Toda lengua dispone de un sistema de signos no verbales específicos. Cuando una persona bilingüe cambia de idioma, también se alteran su lenguaje corporal, sus gestos y sus movimientos de párpados, ejemplifica Fast [1986]. Lenguaje verbal y no verbal están unidos en la comunicación. La cinesis de una lengua se aprende al mismo tiempo que sus otros aspectos. No en vano, se afirman las posibilidades únicas que ofrece el teatro como medio didáctico para el aprendizaje de las lenguas extranjeras al permitir vivir el nuevo idioma y su progresiva asimilación con todo el cuerpo. (Tejerina 1994:107)

L'aprenentatge lingüístic s'efectua amb el treball del llenguatge en situacions concretes d'enunciació. S'ha de tenir en compte que el llenguatge verbal és només un component de la comunicació, el qual sorgeix d'un conjunt d'elements contextuals i de factors 
concrets $\mathrm{i}$ individuals en els fenòmens lingüístics. El teatre té molt en compte el sentit social de la comunicació i possibilita un aprenentatge:

sensible, no teórico, vívido y fácil de asimilar, que beneficia el lenguaje oral, el escrito y el gusto por la lectura. En el plano de la oralidad, facilita un diálogo auténtico y un intercambio real entre los alumnos. Alrededor de un proyecto común. (Tejerina 1994:284)

Motos (1993) i Motos i Navarro (2003) defensen que les tècniques dramàtiques creen un marc comunicatiu que permet el treball de molts tipus de discurs amb una interacció real. Des d'aquesta mateixa perspectiva, Dougill (1987) defensa allò que ell anomena drama activities:

[...] establishing situations in the classroom in which students employ language in a meaninful manner. This derives from the basic tenet that language is above all means of communication, not an abstract body of knowledge to be learnt. (p. 5)

Dougill (1987) pensa que en les classes de llengua tradicionals es descontextualitza la comunicació i se simplifica, fet que contrasta amb la infinitat de situacions i possibilitats de la comunicació real. En algunes activitats dramàtiques, com la improvisació, es produeix una comunicació contextualitzada que apropa l'alumnat a situacions reals on pot desenvolupar estratègies comunicatives de diferent tipus.

Drama activities help to bridge the gap between the cosy and controlled world of the classroom and seemingly chaotic composition of language in the world. (Dougill 1987:6)

D'altra banda, les activitats dramàtiques permeten crear o dinamitzar textos per convertir-los en material dramàtic. ${ }^{3}$ El treball del text teatral és necessari per a la seva representació i això suposa una eina molt interessant per a la didàctica de la llengua i la literatura. A més, el text teatral és un acte comunicatiu potencial, i permet la seva anàlisi contextualitzada amb una finalitat significativa i participativa. 
Preparar una representación teatral, además de un disfrute básico, implica trabajar con un texto para ser dicho, teniendo presente el espectadordestinatario, cuya presencia influye en la voz y sus registros, en los cambios de ritmo, de tono o de texto. Preparar la puesta en escena de un texto obliga a detenerse en la adecuación de las palabras para lograr una ajustada interpretación del mensaje: un actor habla para otro a fin de que sea bien comprendido por un espectador. Esta complejidad de la situación comunicativa que la ficción representada ofrece obliga a "ver" el texto desde ángulos diversos y da mayor conciencia de las relaciones entre emoción, sentido, sonoridad, silencio, palabra, memoria, gesto y acción, ligados estrechamente a otros factores determinantes: el espacio y el tiempo. (Lomas i Ruiz Bikandi 1999:6).

Amb la voluntat de crear pràctiques innovadores en l'acollida d'alumnat nouvingut a través de la dramatització com a instrument didàctic per a l'adquisició lingüística i la formació literària es presenta aquest article, les conclusions del qual es basen en els resultats d'una recerca, situada en el marc de les aplicacions de la literatura en contextos plurilingües, que s'anirà desglossant en les properes pàgines.

\section{La recerca}

Al nostre país, a diferència de països anglosaxons o francòfons, no existeix una tradició en l'ús de la dramatització a les aules més enllà d'algunes representacions aïllades. Per aquest motiu, des de la didàctica de la llengua i la literatura existeixen pocs estudis sobre les possibilitats de la dramatització com a instrument didàctic per a l'adquisició lingüística i la formació literària. No obstant, des de la didàctica de la dramatització sí han aparegut algunes propostes que assenyalen les activitats dramàtiques com instruments eficaços per a l'ús de la llengua i la importància del treball dels textos per ésser dramatitzats.

La recerca que es presenta és un treball exploratori que constitueix una primera aproximació a l'estudi de la dramatització des de la didàctica de la llengua i la literatura (Luengo 2010). Els objectius de la recerca es divideixen en dues vessants: d'una banda, la referent a l'ús que l'alumnat fa de la llengua durant les activitats de dramatització; 
d'una altra banda, la que fa referència a l'activitat literària que es produeix durant el treball dels textos des de la primera lectura fins als assajos i la representació.

En primer lloc, la recerca es planteja si la dramatització d'un text provoca la necessitat de parlar i quina és l'activitat lingüística que es produeix. En aquest sentit, s'ha analitzat la producció de sis alumnes durant les diferents activitats de discussió literària, transformació dels textos i activitats d'interpretació. També s'han analitzat algunes situacions durant la discussió sobre el text per comprovar si es produeixen seqüències potencials per a l'adquisició lingüística.

En segon lloc, s'ha analitzat a grans trets l'activitat literària, des de la perspectiva de les respostes lectores durant l'activitat de discussió del text i el que hem anomenat els retorns al text durant les activitats de representació de rols. Els retorns al text són les necessitats que es produeixen en els actors de comentar alguns aspectes de l'obra en enfrontar-se a la seva representació.

\section{Context de la recerca}

A partir de l'elaboració d'un marc teòric sobre la dramatització com a instrument didàctic i com a eina pedagògica, es va dissenyar una seqüència didàctica (SD) que s'adigués als objectius de la recerca i que recollís les característiques que han de tenir les sessions dels tallers de teatre, situant al centre la interpretació i deixant espai als jocs de desinhibició i jocs dramàtics, com un instrument per superar bloquejos expressius.

La dramatització es concep com tot un seguit d'activitats per al treball de totes les capacitats expressives, incloent la corporal i la verbal. A més, des de la psicopedagogia s'ha estudiat com aquesta disciplina promou el desenvolupament cognitiu i el desenvolupament d'habilitats socials. Això és possible gràcies al gran ventall d'exercicis i de dinàmiques que inclou la dramatització i que no es redueixen a la representació de textos. Els jocs de desinhibició, els jocs de folklore tradicional, la lectura expressiva, els jocs de representació de rols, treballs d'expressió corporal, o les improvisacions són només algunes de les tècniques que proposa aquesta disciplina i que es van incloure en el disseny de la SD. Aquestes activitats, a més d'escalfar i preparar l'alumnat per al treball actoral, promou el desenvolupament expressiu, estètic i afectiu de l'alumnat.

Quant al treball amb textos, la dramatització també ofereix un ventall ampli de possibiliats. Els textos es poden adaptar per ésser representats, es poden narrar oralment, 
es poden utilitzar com a model de conflicte a partir del qual crear un text per representar, es poden transformar a l'estil directe $\mathrm{i}$ crear diàlegs $\mathrm{o}$ es poden treballar diferents estratègies de comprensió a través de la representació de personatges, o diàlegs i entrevistes amb personatges, per exemple. A més, com a activitat artística, possibilita la representació davant d'un públic, que pot ser més o menys extens ( els companys i les companyes de classe, l'alumnat de l'institut, les famílies, etc.), fet que converteix l'activitat en significativa, per la seva repercussió social.

Per a la representació de rols, davant d'un públic o no, cal un treball del text per tal que l'alumnat el faci seu. És necessari realitzar activitats que aprofundeixin en la comprensió i interpretació del text, que incloguin una immersió en els personatges que s'han d'interpretar.

D'altra banda, la dramatització requereix d'un treball expressiu molt important $\mathrm{i}$ que repercuteix sobre l'ús oral de la llengua que s'està adquirint. D'activitats que treballin les capacitats expressives n'hi ha moltes i han estat descrites per la didàctica de la dramatització. Aquestes activitats tenen una funció molt important com a deinhibidores i com a superadores de bloquejos expressius, promovent que l'alumnat es llenci a parlar.

Tenint en compte aquests aspectes, la SD que es va dissenyar per aplicar a les aules té l'estructura d'un taller de teatre, que inclou totes aquestes activitats de dramatització, activitats de dinamització de textos i jocs de representació de rols que es tradueixen en assajos per a la representació de personatges. Els jocs del folklore del país d'acollida poden prendre en aquest sentit un protagonisme excepcional, ja que molts d'ells contenen jocs lingüístics i d'ells se'n desprenen molts trets culturals del país. Les activitats de dramatització de textos, doncs, constitueixen el marc comunicatiu en el qual utilitzar el català.

La SD es va implementar a dues aules d'acollida de dos instituts situats en barris amb un índex alt de població nouvinguda, on l'ús social de la llengua catalana és molt reduït. En aquests contextos l'ús del català es redueix a l'àmbit educatiu, on de vegades resulta complicat crear un context social d'ús. En la recerca van participar quinze alumnes de primer cicle d'ESO.

Un cop establerts els grups, s'ha realitzat una observació de cadascun dels membres durant dues sessions de classe conduïdes per la professora de l'aula d'acollida. Durant aquestes sessions s'han pres notes sobre l'actitud de l'alumnat davant de la 
feina, sobre la seva participació i sobre el seu comportament lingüístic amb la professora i amb els seus iguals.

El treball de dramatització es va realitzar a partir d'un desencadenant del joc (Barret 1985) que era l'àlbum il-lustrat Guineu, de Margaret Wild i Ron Brooks. L'àlbum, que conté un conflicte emocional que podia ser proper a l'alumnat i que era ric en vocabulari, es va establir com a un instrument eficaç per promoure les reflexions literàries en les activitats de discussió de l'àlbum i en les activitats de transformació del text en material dramàtic.

Els àlbums il·lustrats, per les seves caracerístiques, són adients per al treball amb alumnat nouvingut, en facilitar la comprensió de les situacions narrades gràcies al paper que juguen les imatges. El fet de basar-se en propostes narratives que utilitzen la interrelació de text i imatge pot oferir recursos per construir la interpretació de les lectures. A més, el fet de tenir en compte les habilitats visuals sembla un element clau per al desenvolupament de les capacitats culturals, de les habilitats socials i les estratègies de lectura i escriptura (Kiefer 1995).

Establir què defineix un llibre àlbum no és una tasca senzilla i més si es té en compte el fet que és un gènere emergent i que, per tant, presenta característiques diverses i canviants en funció de l'objectiu que cada autoria persegueix. La gran majoria dels estudis sembla estar d'acord que els àlbums utilitzen dos codis diferents $i$ al mateix temps complementaris: el text escrit i la imatge, encara que les perspectives varien en observar la interacció que s'estableix entre ambdós. Tot i això, aquesta premissa sembla complir-se en la majoria de casos.

La idea de un buen álbum es que todos los elementos del libro se pongan en juego al servicio de la historia. El texto y la ilustración [...] pero también el formato, el fondo de la página, la disposición de los elementos en ella, la tipografía, etc. Por eso se dice que "en el álbum todo cuenta" y esto es cierto en las dos acepciones de "contar" (Colomer 2002:20).

\section{Comentari dels resultats}

Dramatització $i$ adquisició lingüistica: D’una banda, es presenten les conclusions relatives a un estudi sobre la participació a partir de les produccions de l'alumnat durant la implementació de la SD. D’altra banda, es fa una descripció de l'ús de les llengües 
durant les activitats i sobre alguns fenòmens relacionats amb la producció oral que constitueixen situacions potencials per a l'adquisició lingüística. En aquests dos aspectes, l'estudi se centra en l'anàlisi de sis casos.

En primer lloc, s'ha fet un estudi de la producció de sis alumnes durant la implementació de la SD per comparar-la amb els seus comportaments lingüístics durant la fase d'observació prèvia. Existeix una diferència entre les dades recollides durant la fase d'observació i les dades que es desprenen de l'anàlisi quantitativa de la situació comunicativa. Aquesta assimetria en el tipus de dades no fa possible arribar a conclusions definitives, però sí que permet apuntar tendències sobre els canvis en la participació i, per tant, en l'ús de la llengua que fa l'alumnat.

En analitzar els resultats s'ha pogut observar com la comparació de les dades extretes de l'anàlisi quantitativa de la producció de l'alumnat i les observacions prèvies, fetes per l'investigador i les professores, apunta una tendència clara cap a un canvi en el comportament lingüístic de l'alumnat durant les activitats proposades en la SD. Sembla que els jocs d'escalfament i desinhibició i que les activitats de discussió i interpretació amb una tasca final promouen l'ús de la llengua i la superació d'alguns bloquejos lingüístics, probablement per la priorització de la tasca i per la creació d'un ambient que permet parlar concebent els problemes lingüístics no com a errors, sinó com a construcció col·lectiva de la comunicació. Aquests canvis es poden observar de forma més clara amb alguns exemples.

L'Abdel és un alumne que participa a les activitats només quan aquestes li interessen; si no és així, es manté passiu. El seu comportament durant la fase d'observació contrasta amb el volum de participació durant la SD: esdevé la més alta de totes les persones participants. Es podria determinar, en comparar-la amb la dels seus companys i companyes, que el seu interès per les activitats proposades és alt.

La Laura, una alumna participativa $\mathrm{i}$ atenta, produeix un nombre elevat d'intervencions, sobretot durant les activitats d'interpretació de rols. Un dels motius d'aquest increment és l'assumpció del rol de directora durant les activitats de dramatització. Es veu, doncs, com les activitats de dramatització permeten la implicació de les persones participants des de diferents perspectives: interpretant dramàticament o construint les escenes des del rol de directors d'escena.

El Julio, un alumne amb una experiència migratòria traumàtica, amb bastants bloquejos amb la llengua i poc participatiu, intervé poc durant la SD. No obstant és 
significativa la seva participació, ja que pel que s'havia observat durant les classes anteriors a la SD i pel que fa a les observacions de la professora, no intervenia gairebé mai. Sembla, doncs, que les activitats proposades promouen l'ús de la llengua, malgrat que en una proporció menor respecte als seus companys i companyes.

La professora del Teo diu d'ell que "és gandul i no posa de la seva part". De fet, uns mesos després de la intervenció a l'aula va ser expulsat de l'aula d'acollida "per no aprofitar-la". No obstant, la seva participació en la SD és alta. Les seves produccions són molt pertinents i ajuden a construir coneixements de forma conjunta. El Teo, a més, és un exemple de la implicació afectiva amb el text, que es reflecteix en la seva alta participació durant les activitats de dinamització de l'obra.

En segon lloc, s'exposen alguns resultats relatius a l'anàlisi de les llengües emprades durant les activitats. De les dades es desprèn que la llengua materna dels i les participants té una influència directa en l'ús del català en les diferents produccions. S'observen diferències importants en l'ús de la llengua que fa cadascun dels i les participants. D'una banda, s'evidencia que el percentatge d'ús del castellà és significativament més alt respecte a l'ús del català entre els i les alumnes castellanoparlants. Per la seva banda, l'alumnat que no té el castellà com a llengua materna presenta unes diferències menors entre l'ús d'ambdues llengües, fins i tot el català és preponderant en alguns casos.

En tercer lloc, s'han analitzat els fenòmens relatius als canvis de llengua que es produeixen. Aquesta anàlisi té la intenció de mostrar alguns fenòmens que provoquen la reflexió sobre les llengües utilitzades i sobre els problemes que puguin sorgir en la comunicació. Per solucionar-los, es pot fer necessari utilitzar estratègies que poden esdevenir seqüències potencials per a l'adquisició lingüística.

Es pot observar com els canvis de llengua responen, d'una banda, a bloquejos expressius, a través de l'anàlisi quantitativa del nombre de mots. Es presenta a continuació un exemple de bloquejos expressius, fruit de l'enfrontament dels aprenents i les aprenentes amb la llengua en ús. 
Figura 1. Fragment de la transcripció de la primera sessió (Simbologia en l'apèndix 1)

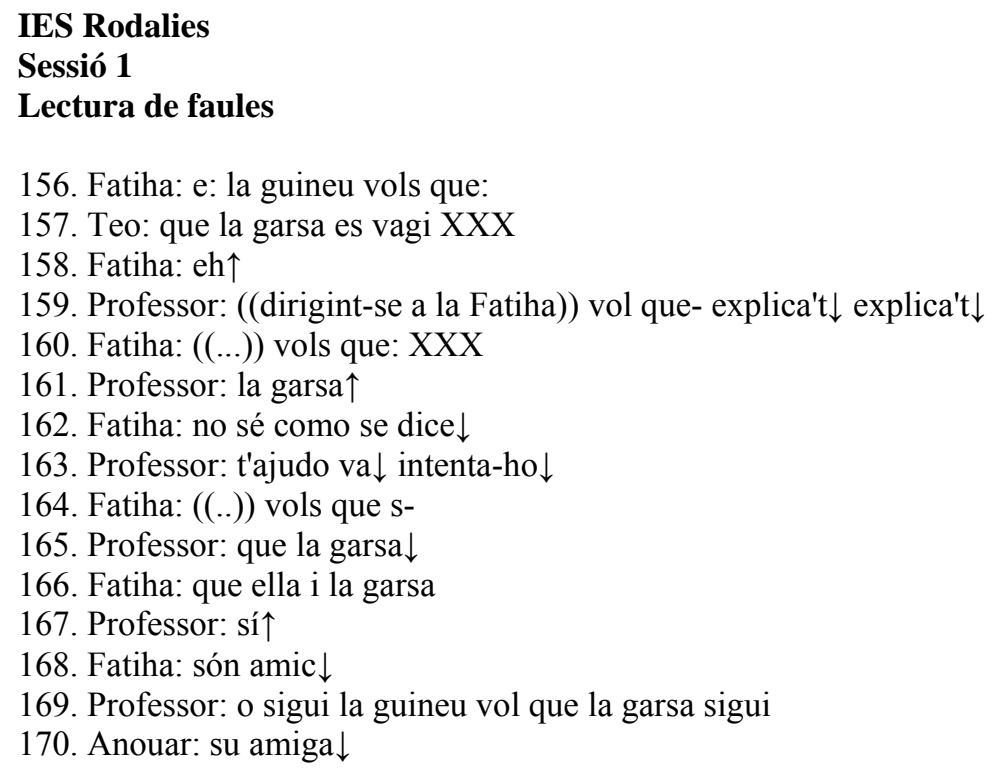

Aquestes situacions creen la possibilitat que es produeixin seqüències potencials per a l'adquisició (SPA) en què els i les companyes i la persona parlant nativa aportin estratègies de bricolatge interactiu ${ }^{4}$ (Py 1994b, citat per Guasch 1999). L'aprofitament o no d'aquestes SPA per a l'aprenentatge lingüístic depèn fortament de les estratègies que siguin utilitzades per les persones participants en el rol d'expertes i de la possibilitat que existeixi interacció en aquest sentit.

La tensió entre les dues llengües en el seu ús mostra l'esforç que fa l'alumnat per parlar en català i com les estratègies de facilitació de la comunicació mostren un interès en aquest mateix sentit.

Aquestes seqüències donen peu a l'activitat metalingüística com a estratègia per solucionar les dificultats que sorgeixen durant la interacció. Així doncs, es pot afirmar que durant l'activitat de dinamització del text a través de la interpretació sorgeixen possibilitats de reflexionar sobre la llengua en un context concret.

Dramatització i formació literària: La programació que s'ha implementat a les dues aules té un marcat caràcter literari, ja que la columna vertebral és la dramatització d'un àlbum il-lustrat. Com s'ha explicat en apartats precedents, diverses activitats de la SD tenen la funció de construir i aprofundir en la comprensió literària de l'obra: des de la discussió literària a la dramatització del text. En el treball de recerca s'han analitzat les 
respostes lectores de l'estudiantat durant les activitats de discussió de l'àlbum. Existeixen diversos estudis que, amb gran profunditat, analitzen aquestes respostes en aquest tipus d'activitats. Per aquest motiu, aquest article se centrarà en aportar algunes conclusions provisionals relatives als retorns al text que l'alumnat produeix durant les activitats de representació de rols, que no s'han estudiat a fons en d'altres treballs.

Durant les activitats d'interpretació es fa necessari recórrer en nombroses ocasions al text que s'està dinamitzant. Les raons que obliguen l'alumnat a comentar parts del text són diverses i donen compte de la potencialitat d'aquestes activitats per seguir aprofundint en la comprensió i interpretació de l'obra. S'ha realitzat una classificació d'aquests motius: (a) en primer lloc, cal que aquesta obra protagonitzada per animals s'adapti per a què els personatges siguin humans; (b) en segon lloc, cal aprofundir en els personatges per poder-los interpretar; (c) en tercer lloc, cal comentar alguns elements de l'estructura de la trama; (d) finalment, cal comentar alguns aspectes de les diferències entre el text narratiu i el gènere dramàtic per poder adaptar les interpretacions dels personatges.

(a) Trobem alguns exemples en què l'alumnat discuteix per adaptar els personatges i el context animals a humans, creant elements paral·lels a la història que no facin canviar l'estructura ni el significat del llibre que s'està adaptant per a la dramatització. En fer aquesta adaptació l'alumnat ha d'haver assimilat elements complexos de la història i de la trama $\mathrm{i}$ ha d'haver aprofundit en aspectes relatius a la interpretació de l'obra i a la idea o idees centrals del text.

Figura 2. Fragment de la transcripció de la tercera sessió

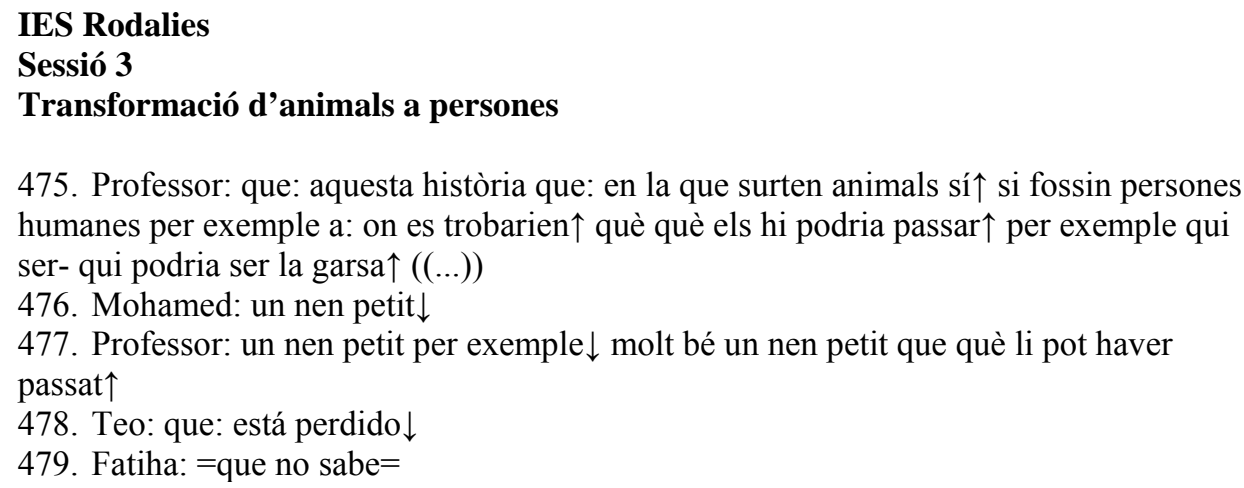


(b) Per poder interpretar un personatge cal una reflexió sobre la seva personalitat i la seva forma d'actuar per captar els matisos que permetran interpretar-lo. Durant les activitats d'interpretació trobem diversos exemples en què l'estudiantat es planteja com se senten els personatges en els diferents moments i com hauran d'actuar. Les ajudes dels i les companyes són cabdals per anar provant formes d'interpretar, partint de les pistes que li ofereixen a l'actor o a l'actriu, construint així la interpretació de forma conjunta.

Figura 3. Fragment de la transcripció de la quarta sessió

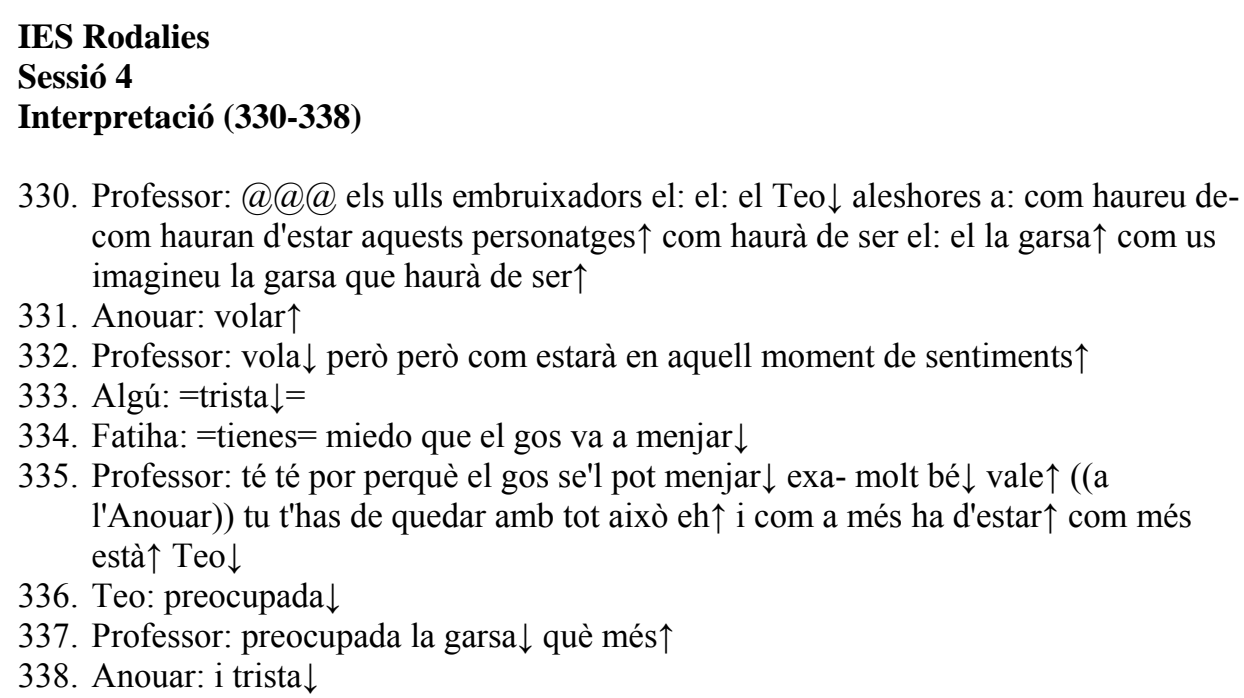

330. Professor:@@els ulls embruixadors el: el: el Teo $\downarrow$ aleshores a: com haureu decom hauran d'estar aquests personatges $\uparrow$ com haurà de ser el: el la garsa $\uparrow$ com us imagineu la garsa que haurà de ser $\uparrow$

331. Anouar: volar $\uparrow$

332. Professor: vola $\downarrow$ però però com estarà en aquell moment de sentiments $\uparrow$

333. Algú: $=$ trista $\downarrow=$

334. Fatiha: $=$ tienes $=$ miedo que el gos va a menjar $\downarrow$

335. Professor: té té por perquè el gos se'l pot menjar $\downarrow$ exa- molt bé $\downarrow$ vale $\uparrow$ ((a l'Anouar)) tu t'has de quedar amb tot això eh $\uparrow$ i com a més ha d'estar $\uparrow$ com més està $\uparrow$ Teo $\downarrow$

336. Teo: preocupada $\downarrow$

337. Professor: preocupada la garsa $\downarrow$ què més $\uparrow$

338. Anouar: i trista $\downarrow$

(c) Quan s'estan construint les escenes, cal adaptar la història explicada al gènere teatral i construir la trama de tal forma que es conservi la força amb què, en l'obra original, es transmeten les idees del text.

Figura 4. Fragment de la transcripció de la tercera sessió

\section{IES Barcelona \\ Sessió 3 \\ Interpretació (161-170)}

161. Victoria: no perquè cuando el el: el gos estaba bebiendo agua la- la garsa estaba preparada pa comer XXX cosas de la guineu mala XXX

162. Laura: no pero eso es al principi quan ja

163. Professor: al principi de tot

164. Laura: el principio de todo $\downarrow$ do $\downarrow$

165. Abdel: cuando te quemaste la alita $\downarrow$ te quemaste la alita $\downarrow$

166. Professor: què passava $\uparrow$ diga- diga-li què passava Laura

167. Laura: que estaba estirada llorando triste y el gos venía y le cogía la boca

168. Abdel: le cogía la boca le cogía por la boca $\downarrow$

169. Laura: le cogía con la boca

170. Victoria: $\{($ @)tú me vas a coger a mí con la boca $\uparrow\}$ ((li diu al Julio)) 
(d) En l'adaptació d'un text narratiu per transformar-lo en material dramàtic cal reflexionar sobre els elements del gènere. L'existència d'un narrador possibilita l'aparició de comentaris inserits en les intervencions dels personatges per fer l'obra més comprensible. En el teatre, en canvi, les intervencions es realitzen en estil directe. Cal que l'alumnat tingui clars aquests aspectes propis dels gèneres i durant la reescriptura de l'obra.

Figura 5. Fragment de la transcripció de la tercera sessió

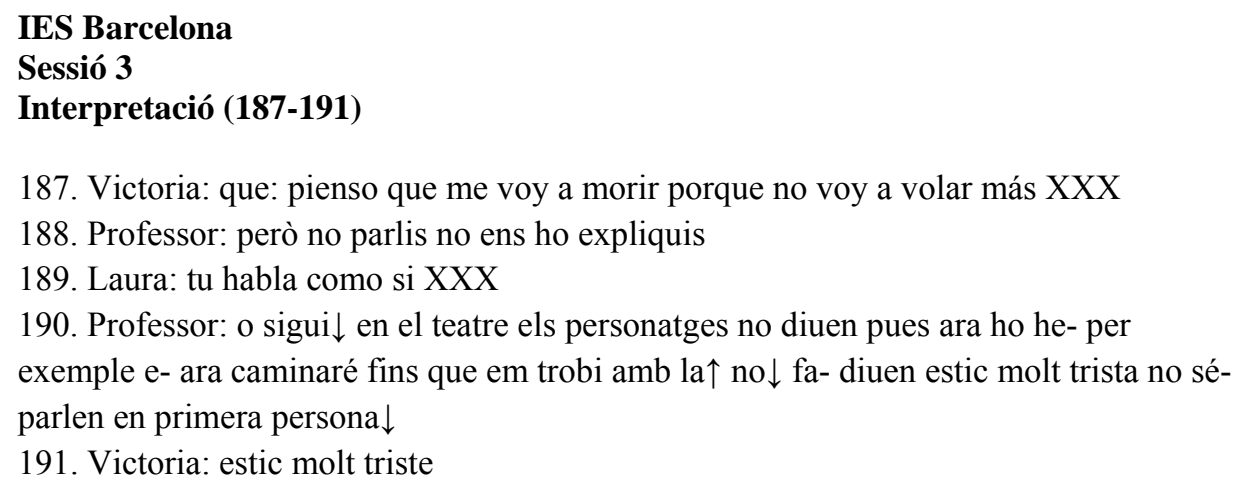

A les activitats d'interpretació la comprensió de l'obra està molt lligada a un aprenentatge significatiu amb un objectiu molt funcional: dramatitzar. L'alumnat recorre al text per construir els personatges i per construir les escenes. També necessita plantejar-se qüestions relatives a l'adaptació o a l'ordre de la trama i, en el cas de la SD dissenyada a partir d'un àlbum il·lustrat, necessita enfrontar-se a l'adaptació d'un gènere narratiu a un gènere dramàtic.

Sembla, doncs, que les activitats proposades per la SD permeten una reflexió profunda sobre les característiques de l'àlbum il·lustrat i estableixen un lligam entre alumne i text. Les operacions que preparen l'actor per a la interpretació són paral·leles a algunes de les respostes lectores de l'alumnat, que també recorren a la descripció de les escenes, a la interpretació dels motius del text i parteixen de l'experiència personal o de situacions properes per aprofundir en l'obra $\mathrm{i}$ en els personatges a través de la interpretació. L'activitat de dramatització de l'obra provoca per si mateixa la reflexió sobre l'obra treballada i fa que l'alumnat s'enfronti en un context d'ús a problemes derivats del treball i interpretació del text. 


\section{Conclusions}

Els resultats d'aquesta primera exploració mostren com les activitats dramàtiques dins una seqüència didàctica promouen l'aprenentatge literari i l'ús de la llengua, lligat a l'adquisició lingüística gràcies a la necessitat d'utilitzar estratègies d'ajuda, suport i facilitació de la comunicació, que poden ser utilitzades, a més, pel mediador per promoure la reflexió lingüística.

La dramatització s'estableix com una activitat efectiva en la conjuminació del treball lingüístic i literari, ja que promou la comunicació oral i la necessitat de reflexionar en profunditat sobre els textos treballats. Tot i això, alguns d'aquests primers resultats s'hauran d'estudiar en recerques posteriors amb més profunditat.

Seria interessant que l'escola propiciés més espais per al treball de la dramatització, que a més d'estar lligada a l'ús de la llengua i a la reflexió literària, promou l'ús de les diferents capacitats expressives i creatives de l'ésser humà, constitueix un desafiament que permet la reflexió sobre un o una mateixa i sobre l'entorn i es proposa la formació integral de l'alumnat.

\section{Referències bibliogràfiques}

Barret, G. (1985) El teatro como materia programada en el proceso de aprendizaje. A Poveda, L. (ed.) Ser o no ser, pp. 127-162. Madrid: Narcea.

Brooks, R. i Wild, M. (2005) Guineu. Barcelona: Ekaré.

Casado, R. (2003) Parlar és actuar. El teatre com a eina d'expressió oral per a no catalanoparlants. Articles de Didàctica de la Llengua i de la Literatura, 29: 29-40.

Colomer, T. (dir.) (2002) Siete llaves para valorar las historias infantiles. Madrid: Fundación Germán Sánchez Ruipérez.

Dougill, J. (1987) Drama activities for language learning. Londres: Macmillan.

Guasch, O. (1999) Processos de composició escrita i programes d'immersió: Els canvis de llengua en la interacció per a la composició en L2. Tesi doctoral no publicada. Universitat Autònoma de Barcelona.

Kiefer, B. (1995) The Potential of Picture Books: From Visual Literacy to Aesthetic Understanding. Englewood Cliff, NJ: Merrill.

Lomas, C. i Ruiz Bikandi, U. (1999) Teatro y juego dramático. Textos de Didáctica de la Lengua y de la Literatura, 19: 5-8.

Luengo, A. (2010) Actuar per parlar. La dramatització com a instrument per a l'adquisició lingüística i la formació literària a dues aules d'acollida. Treball de recerca no publicat. Universitat Autònoma de Barcelona.

Margallo, A-M. (2008) Utilització de textos literaris per a la integració i l'aprenentatge lingüistic de l'alumnat nouvingut. Proposta de corpus. Llicència d'estudis de la Generalitat de Catalunya no publicada. Universitat Autònoma de Barcelona. 
Motos, T. (1993) Las técnicas dramáticas: procedimiento didáctico para la enseñanza de la lengua y la literatura. Enseñanza. Anuario interuniversitario de didáctica, 1011: 75-94.

Motos, T. i Navarro, A. (2003) El paper de la dramatització al currículum. Articles de Didàctica de la Llengua i de la Literatura, 29: 10-28.

Tejerina, I. (1994) Dramatización y teatro infantil. Dimensiones psicopedagógicas y expresivas. Madrid: Siglo XXI.

Murgades, Josep (coord.) (2006) "Conclusions de la comissió de Didàctica de la literatura. L'ensenyament de la literatura a l'ensenyament no universitari". Dins de Consell assessor de la llengua a l'escola: Conclusions. Barcelona: Generalitat de Catalunya.

\title{
Apèndix 1
}

\author{
Simbologia de les transcripcions \\ $\uparrow$ Entonación ascendente. \\ $\downarrow$ Entonación descendente. \\ $=$ texto hablante $\mathrm{A}=$ \\ $=$ texto hablante $\mathrm{B}=$ Encabalgamiento. \\ $\{(\mathrm{P})$ texto $\}$ Piano (baja intensidad). \\ $\{(\mathrm{PP})$ texto $\}$ Pianissimo (muy baja intensidad). \\ $\{($ F)text $\}$ Forte (alta intensidad). \\ TEXTO (en mayúsculas) Fortissimo (muy alta intensidad). \\ $\{($ @) texto\} Enunciado acompañado de risa. \\ \{@@\}, Risas. \\ $\{(?)$ texto $\}$ Fragmento dudoso.
}

XXX | XXX XXX | XXX XXX XXX Fragmento incomprensible (según duración, de menor a mayor respectivamente).

[...] Fragmento extraído.

[texto] Fragmento o palabra agregada por la transcriptora para hacer más comprensible el comentario texto: Alargamiento silábico (según la duración, de menor a mayor respectivamente).

((..)) Pausa de dos segundos.

((...)) Pausa de tres segundos.

((texto)) Comentario de la transcriptora.

\footnotetext{
1 Alguns centres educatius han adoptat altres models per a l'acollida d'alumnat nouvingut, ja que han considerat que per a aconseguir els objectius d'integració no es pot optar per una metodologia que consideren no inclusiva dins de l'aula ordinària.

${ }^{2}$ Grup de Recerca en Literatura Infantil i Juvenil i Educació Literària de la Universitat Autònoma de Barcelona. L'equip GRETEL està dirigit per la doctora Teresa Colomer i actualment Gretel té el reconeixement de Grup de recerca de qualitat de la Generalitat de Catalunya (2009SGR1477) (20092014). D'entre els projectes que s'estan desenvolupant destaca el projecte de recerca I+D (I+D: EDU2008-02131/EDUC) del Ministerio de Educación y Ciencia (convocatòria de 2008), "La interpretació literària d'àlbums il·lustrats en el procés d'acollida d'alumnes immigrants".

${ }^{3}$ La dinamització (Motos 2003) es refereix a les activitats en què es treballa el text per aprofundir en la seva comprensió i interpretació.

${ }^{4}$ El bricolatge interactiu o la improvisació cojuntural són els conjunt d'estratègies adapatives que poden resoldre problemes derivats de la distància intercultural $i$ de la diferència de posicionament de cadascun dels interlocutors respecte del codi emprat en l'intercanvi.
}

\section{Referència de l'autor:}

Antonio Luengo Bravo és becari d'investigació del Grup de Recerca GRETEL. És llicenciat en Filologia Hispànica i Filologia Catalana per la Universitat Autònoma de Barcelona. Ha cursat el Màster de Recerca en Didàctica de la Llengua i la Literatura a la mateixa universitat i ha realitzat el treball de recerca Actuar per parlar. La dramatització com a instrument didàctic per a l'adquisició lingüística $i$ la formació 
literària a dues aules d'acollida. Actualment cursa la tesi doctoral que s'emmarca en els estudis sobre dramatització i educació literària. També ha cursat el postgrau de Teatre i Educació de l'Institut del Teatre. Té experiència com a docent en l'àmbit de l'educació secundària.

Email: anluengobr@gmail.com 